\title{
Male prisoners' family relationships and resilience in resettlement
}

Criminology \& Criminal Justice 2015, Vol. 15(4) 423-44I

(C) The Author(s) 2015

Reprints and permissions: sagepub.co.uk/journalsPermissions.nav DOI: $10.1177 / 17488958 \mid 4566287$

crj.sagepub.com

\section{Lucy Markson}

Institute of Criminology, University of Cambridge, UK

\section{Friedrich Lösel}

Institute of Criminology, University of Cambridge, UK;

University of Erlangen-Nuremberg, Germany

\section{Karen Souza}

Institute of Criminology, University of Cambridge, UK

\section{Caroline Lanskey}

Institute of Criminology, University of Cambridge, UK

\begin{abstract}
Theories of social bonding and social capital support the argument that positive family relationships are important for resilience in resettlement after release from prison. However, this topic has rarely been addressed in prospective longitudinal studies of resettlement processes. This study gathered interview data from 39 family pairs of British male prisoners and their (ex-)partners before and after release. Questions on the father's relationship, involvement and contact with the family were used as an index to predict seven resettlement outcomes. At the bivariate level and after control of pre-prison risk variables, family relationships predicted positive outcomes with finding accommodation, alcohol and drug use, the extent to which ex-prisoners felt they were coping with resettlement challenges and the quality of post-release family relations. In contrast, difficulties with employment and finance were neither related to previous family relations nor to the other resettlement outcomes. The findings suggest no general protective influence of family
\end{abstract}

\footnotetext{
Corresponding author:

Lucy Markson, Institute of Criminology, University of Cambridge, Sidgwick Avenue, Cambridge CB3 9DA, UK.

Email:Im473@cam.ac.uk
} 
relationships during resettlement, but a strong effect on social and emotional aspects. Theoretical issues, limitations and potential practical consequences are discussed.

\section{Keywords}

Family relationships, prisoners, resettlement, resilient adaptation

Over half of male prisoners in England and Wales have at least one child under the age of 18 and approximately a quarter live with a partner before prison (Ministry of Justice, 2012). Imprisonment of a father is a serious critical life event: it can disrupt family relationships, contribute to negative outcomes for children and aggravate material and social problems such as unemployment and social exclusion (Braman, 2004; Jamieson and Grounds, 2005; Morris, 1965; Murray et al., 2012a, 2012b; Pettit and Lyons, 2009; Wildeman, 2010). Resettlement after release from prison can also present many challenges (e.g. Naser and Visher, 2006; Zamble and Quinsey, 1997). However, most of the research on imprisonment and resettlement has focused on risks, deficits and negative outcomes. Much less is known about the other side of the coin: resilience in response to the challenges of imprisonment and release.

Resilience is a complex construct (e.g. Cicchetti, 2010; Luthar et al., 2000; Masten, 2007; Rutter, 2012) that covers a 'reduced vulnerability to environmental risk experiences, the overcoming of a stress or adversity or a relatively good outcome despite risk experiences' (Rutter, 2012: 336). Whereas early research on resilience investigated personal and social resources that had a rather general protective function, current views agree on dynamic, multi-level social, psychological and biological processes that can vary across individuals, problem types, time and circumstances (Cicchetti, 2010; Lösel and Farrington, 2012; Masten, 2007; Rutter, 2012). The outcome can be defined in terms of specific competences or absence of mental health problems and social difficulties. Parallels can be drawn between the concepts of resilience and desistance, which refers to the process of 'maintaining crime-free behaviour in the face of life's obstacles and frustrations' (Maruna, 2001: 26). Both focus on positive processes and identifying strengths rather than risks or deficits; however, resilience is a broader concept that goes beyond outcomes in offending (Fitzpatrick, 2011).

The resettlement literature, stemming mostly from research in the United Kingdom and United States, shows that upon release offenders typically need support with accommodation, employment, health, alcohol and drugs, finances, family relationships and changing attitudes, thinking and behaviour (e.g. Ministry of Justice, 2010; Prison Reform Trust, 2010; Social Exclusion Unit, 2002; Visher et al., 2006). The evidence suggests that having these needs met can make the difference between reoffending or not (e.g. Bales and Mears, 2008; Baumer et al., 2009; La Vigne et al., 2004; May et al., 2008; Niven and Stewart, 2005; Theobald and Farrington, 2013; Visher and Courtney, 2006). Such personal and social factors are therefore relevant for processes of desistance (e.g. Adorjan and Chui, 2012; Farrall and Calverley, 2006; Laub et al., 1998; LeBel et al., 2008; Maruna, 2001; Sampson and Laub, 1993; Shapland et al., 2012). These findings have 
helped to establish the 'What Works' in reducing reoffending paradigm (e.g. McGuire, 1995), which has directly influenced UK government resettlement policy. For example, the National Offender Management Service's (NOMS) reducing reoffending model (Home Office, 2004) targets seven 'pathways to reducing reoffending' (accommodation, education, training and employment, health, alcohol and drugs, finances, benefits and debts, children and families, and attitudes, thinking and behaviour) in its work with male offenders.

Although there is clear overlap between the concepts of desistance and resilience, there have been surprisingly few links to the latter topic in criminology (Lösel, 2012a, 2012b). Adopting a broader focus in line with a resilience perspective reflects the reality and complexity of resettlement and reintegration into society after release from prison (Visher and Travis, 2003). Therefore, the present article will apply a more resilienceorientated perspective to resettlement experiences. Both from the perspective of desistance and resilience research the family is a key domain of protective processes (e.g. Adorjan and Chui, 2012; Berg and Huebner, 2011; Collishaw et al., 2007; Farrall, 2004; Flouri, 2006, 2007; La Vigne et al., 2004; Lösel and Bender, 2003; Masten, 2011; Visher and Courtney, 2006, 2007), although family relationships can strain the resettlement process if they support problem behaviours such as drug use (Davis et al., 2012). Nonetheless, the potentially positive role of families in prisoners' resettlement success is increasingly being recognized as an important topic (Ministry of Justice, 2012).

The benefit of a positive family influence in developing and supporting resilience in resettlement can be understood, for example, from social bonding theory and social capital perspectives. A version of control theory, social bonding theory explains offending by the degree to which individuals are connected to society (e.g. Hirschi, 2002). Relationships with others are one mechanism through which an individual may be connected to society. Having an attachment to others facilitates the internalization of societal norms which are shared by those to whom they are attached. This attachment constrains the extent to which the individual deviates from societal norms because they are sensitive to the views of others (Hirschi, 2011). There are three other mechanisms of the bond to society: commitment to goals; involvement in social activities; and endorsement of a common value system. Research supports the theory in finding that such bonds may exert a protective influence, in particular against offending behaviour and drug abuse (Hawkins et al., 1992). They can impact on formal resettlement arrangements (Jackson et al., 2013), for example, by facilitating 'readiness' to change criminal or anti-social lifestyles (Maguire and Raynor, 2006) and enhancing the resettling prisoner's ability to cope and adapt successfully (Maruna, 2001).

Social capital refers to the real or possible resources that result from membership of a supporting group that shares collective capital (Bourdieu, 1986). This group membership provides 'a knowledge and sense of obligations, expectations, trustworthiness, information channels, norms and sanctions' (Hagan and McCarthy, 1997: 229). Social capital is related to less crime in neighbourhoods and resilience to crime (e.g. Field, 2003; Rosenfeld et al., 2001). The respective data is often on an aggregate level, however, it has also been shown that social capital is relevant for turning points in life and desistance from crime in individual development (e.g. Farrall, 2004; Laub and Sampson, 2003; Sampson and Laub, 1993). Accordingly, social capital provided via the family network 
may be useful to ex-prisoners in resettlement, for example by fostering motivation to desist from crime through affirming norms, values and expectations as well as providing practical support such as accommodation and employment opportunities (Mills and Codd, 2008).

Although theories of social bonding and social capital suggest that family relations can support resilience in resettlement this topic has rarely been addressed in prospective longitudinal studies. Therefore, using a prospective longitudinal design, multiple informants and controlling for the influence of third variables that may also influence outcomes, this study investigates whether pre-prison family relationships and family contact during the imprisonment support prisoners in developing resilience to the hardship of reintegration after a prison sentence, as measured by seven important areas of resettlement: accommodation; employment; health; alcohol and drugs; finances; family relationships; and coping ability.

\section{Method}

\section{Design}

The data stem from the research project Risk and Protective Factors in the Resettlement of Imprisoned Fathers with Their Families (Lösel et al., 2012). This project was the first prospective longitudinal study in Europe to investigate the resettlement of imprisoned fathers and their families that gathered data from family sets of the man, woman and children. Data were collected at two key stages in the resettlement process (hereafter referred to as Time 1 and Time 2). Time 1 interviews with prisoners, their (ex-)partners (i.e. the children's mother) and children were conducted within four months before the men were released. Time 2 interviews were conducted within approximately six months after release. This article presents data from the men and their female (ex-)partners. For data on the children see Lanskey et al. (2014).

\section{Sample}

The prisoners were recruited from eight prisons in the eastern region of England. For practical and scientific reasons, the selection of the sample was based on a set of eligibility criteria: having a partner or ex-partner, having at least one (step)child under the age of 18; being in contact with the family; a sentence length between six months and six years; no sexual or domestic violence index offence; and release within four months to East Anglia or London. If the prisoner had children with more than one woman, he was asked to nominate his current relationship or the family with whom he was most closely linked before his imprisonment for his current sentence. Due to limited resources and the characteristics of our sample prisons we focused on male prisoners' family relationships. None of the men approached by the researchers reported having children within a samesex relationship. The limitations of this approach to conceptualizing the family are acknowledged in the discussion section.

Consent to take part was required from both the man and the woman in each family for inclusion in the study. A total of 668 prisoners were approached based on referrals 
from prison staff. However, the detailed check of family status and other selection criteria reduced the number to 252 eligible prisoners. First consent was obtained from 103 of these men and second consent from 54 of the (ex-)partners. Therefore, the Time 1 (during imprisonment) sample comprised 54 prisoners, 54 (ex-)partners and 90 children. At Time 2 (after release), 40 men, 49 women and 80 children participated. The respective retention rates were 74.1 per cent for the men, 90.7 per cent for the women and 88.9 per cent for the children. The data used in the present article are from the families of which both the man and woman participated at Time 1 and Time 2. One family was removed from the analysis because the man was still imprisoned at the scheduled time of the postrelease interview. Therefore, the analysis is based on 39 families.

At Time 1, the mean age of the prisoners was 32.10 years $(\mathrm{SD}=10.47)$. Eighty per cent were White British, and the remainder was from Black and Asian Minority Ethnic (BAME) groups. The highest proportion were serving sentences for violence against a person (33.0 per cent), followed by 28.3 per cent for acquisitive crimes (i.e. burglary, robbery, theft and handling), and drug offences (17.9 per cent). The sample was broadly comparable to the national male prison population according to age (Prison Reform Trust, 2009) and offence type (Berman, 2011). The mean sentence length was 2.3 years $(\mathrm{SD}=1.31)$. The mean age of the $(\mathrm{ex}-)$ partners was 29.36 years $(\mathrm{SD}=8.26)$. The majority were also White British (82.1 per cent). At Time 1, 84.6 per cent of the men reported being in a relationship with the woman. At Time 2, this figure was 74.3 per cent.

Analyses were conducted to assess whether there were systematic differences in the characteristics of men who completed both Time 1 and Time 2 interviews and those who declined to take part at Time 2 . There were no significant differences in various offending characteristics and demographic variables except ethnicity. Men of White British ethnicity were more likely than men of BAME groups to take part at Time $2(p<0.05)$. Therefore, the data suggest a slight selection effect over time in which the experiences of BAME families may be underrepresented. At Time 1, BAME and White British men did not differ in their relationship status, their rating of the quality of their relationship with their (ex-)partner or the amount of contact they had with the woman through prison visits (all $p$ s $>0.05)$. There were also no significant differences on these variables between either the BAME $(N=7)$ and White British $(N=7)$ non-completion families who did not take part at Time 2, or between the Time 2 BAME non-completion and the Time 2 BAME completion families.

\section{Procedure}

Access to prisoners and their families was gained via the assistance of staff in the prisons. Due to variations in the prison policies and regimes in our sample, it was necessary to employ different methods of recruitment. Lists of prisoners who fitted the sentence length and release date criteria were obtained from the prisons. Because NOMS does not systematically record information on the children and families of prisoners, potentially eligible prisoners were visited in person, mostly by the research team and sometimes by staff within the prison. In addition, letters were sent to shortlisted prisoners to invite them to attend an information session where the research team explained the aims and purposes of the study. Recruitment also took place by contacting prisoners who had used children and 
families services in the prison as well as at 'association' times. In addition, the research team and prison staff attended prison visitors' centres and visits halls to invite eligible families to participate. Where the man was first invited to participate, he provided contact details for the woman which were followed up by the research team by phone and letter.

Six trained interviewers who had undergone an enhanced security clearance and Criminal Records Bureau (CRB) check carried out interviews. Interviews with the men and women took place separately and lasted approximately one hour and 20 minutes. Pre-release interviews with the prisoners were conducted either via legal visits or on the prison wings. The men's post-release interviews took place at a time and location in the community convenient to them. Likewise, the women's Time 1 and Time 2 interviews were carried out at their convenience (mostly in their homes). The participants were informed that their participation was completely voluntary and that they could withdraw from the research at any time without consequences. They were also assured about the confidentiality and anonymity of reported data. The men and women were additionally informed that the research was independent from the Prison Service and that the men would not be deducted pay for interviews taking place during work hours in prison. In appreciation of their participation, the families were given shopping vouchers after completing the Time $1(£ 10)$ and Time $2(£ 25)$ interviews.

\section{Instruments}

Semi-structured interview schedules for the men and their (ex-)partners were designed to collect quantitative and qualitative data at Time 1 and Time 2 on a broad range of topics relating to criminal history, childhood and family history (fathers only), education and employment, accommodation, family and relationships, child care and parenting, contact during imprisonment, coping, family adjustment, substance use, physical and mental health, prison programmes, education and training, formal and informal support and post-release adjustment. In addition, both partners self-completed standardized questionnaires. In the present article we used the following quantitative measures.

Family relations predictor. To obtain a measure of family relationships, we combined data on the relationship before prison and on contact during the imprisonment. We used data on contact during the imprisonment because research shows that it is important to maintain relationships from before to after the imprisonment (e.g. Bales and Mears, 2008; Baumer et al., 2009; Lanskey et al., 2014; La Vigne et al., 2005). Contact during imprisonment has also been used as a 'proxy measure' of family relationships by other researchers (e.g. Niven and Stewart, 2005).

Pre-prison relationships. Family relationships before the father's imprisonment were measured using two items from Time 1. First, both partners were asked 'How good do you think your relationship was before prison?' This item was rated on a scale of $1=$ 'not at all good' to $5=$ 'extremely good'. The men's and women's scores were significantly positively correlated, $r=0.57, p<0.05$. Responses for the man and woman in each family pair were summed and averaged to provide a multiple informant overall indication of the relationship. 
In addition, each partner was asked 'How much was the father involved with the children in (a) helping with school work, (b) discipline, (c) daily care, (d) play/leisure and (e) discussion and decision making before prison?' Each indicator of involvement was rated on a scale of $1=$ 'not at all involved', to $5=$ 'extremely involved'. The men's and women's scores were significantly positively correlated, $r=0.38, p<0.05$. Ratings across each child in the family were averaged and the men's mean involvement across the five domains was calculated based on each partner's report. The scores for each family pair were summed and the mean across the items was calculated. The reliability of this index was Cronbach's $\alpha=0.67$.

Contact during the imprisonment. This aspect of family relationships was measured using two items from Time 1. The first was 'How often do you have contact through (a) visits, (b) phone calls and (c) total written contact (letters and emails)?' Responses were scored on a scale of $0=$ 'never' to $6=$ 'more than once a week'. Average scores across the types of contact were calculated for each man and woman. The men and women's scores were positively correlated, $r=0.58, p<0.01$, and were combined.

In addition, we also assessed each family pair's ratings of the item 'How much have you talked about the resettlement issues of (a) accommodation, (b) employment, (c) finances, (d) alcohol and (e) drug use, (f) maintaining family relationships and (g) leading a non-criminal lifestyle?' Responses were scored on a scale from $1=$ 'not at all' to 5 $=$ 'a lot'. Average scores across the resettlement issues were calculated for each man and woman. The men's and women's scores were positively correlated, $r=0.42, p<0.05$, and were combined. The reliability of this index of the intensity and quality of family contact was Cronbach's $\alpha=0.61$.

The $\mathrm{z}$ scores of the measures of family relationships before prison and contact during the imprisonment were combined and the mean was calculated. This comprised the overall measure of family relationships.

\section{Resettlement outcomes}

The Time 2 dependent variables broadly reflected the literature on important aspects of resettlement and were based on the men's self-reports.

1. Accommodation. This was measured by the item, 'Since your release, how difficult has finding suitable living arrangements been for you?' Responses were scored from $1=$ 'not at all difficult' to $5=$ 'extremely difficult'.

2. Employment. We used the item, 'Since your release, how difficult has finding a job been for you?' to measure employment outcomes. Responses were scored from $1=$ 'not at all difficult' to $5=$ 'extremely difficult'.

3. Health. The General Health Questionnaire (GHQ-12; Goldberg, 1978) was used to measure psychological health. This scale contains 12 items such as 'Have you recently been feeling unhappy and depressed?', or 'Have you recently been able to concentrate on whatever you're doing?' Each item is answered on a four-point scale (e.g. $0=$ 'not at all' to $4=$ 'much more than usual', or $0=$ 'better than usual' to $4=$ 'much less than usual'). The total score range is 0 to 36 , where high scores indicate more health problems. 
4. Alcohol and drugs. This was measured using the items, 'Since your release, how difficult has alcohol use been for you?' and 'Since your release, how difficult has drug use been for you?' Responses were scored on the scale $1=$ 'not at all difficult' to 5 = 'extremely difficult'. Taking the mean score from the two items was potentially problematic because it could under-represent problems with either drugs or alcohol. Instead, the highest difficulty score from the two ratings was used to give a more appropriate representation of the data.

5. Finances. This was measured by responses to the question, 'Since your release, how difficult has having enough money been for you?' Responses were scored on the scale $1=$ 'not at all difficult' to 5 = 'extremely difficult'.

6. Families. We assessed the man's relationship with the woman after release using the item 'How good do you think your relationship is with your (ex-)partner now?' Responses were rated on the scale $1=$ 'not at all good' to $5=$ 'extremely good'.

7. Coping ability. We applied a scale on coping and resilient adaptation as a rough indicator of the men's thinking patterns, coping behaviour and use of protective social resources (Bender and Lösel, 2009). This contains 13 items such as 'I am very determined to reach my goals', 'I feel that my life is meaningful', 'There is someone in my life I can always trust', 'I can deal well with others', and 'I am confident I can find a solution to most of my problems'. Items were scored on a scale from $1=$ 'not at all true' to $4=$ 'completely true'. The total score range was 13 to 52, where high scores indicate thinking and behaviour that favour successful coping with problems during resettlement. The reliability of the scale was Cronbach's $\alpha=0.81$.

As normal, there were some missing data in the whole data set. As these were rare and random rather than systematic, we applied simple imputing techniques (e.g. Kleinke et al., 2011). We used regression estimation to compute total scores for missing cases on the two standardized measures (GHQ and coping ability scale). The appropriate sample mean or median was assigned to missing data for the outcomes.

\section{Control variables}

In order to investigate the independent predictive power of family relationships we controlled for the possible influence of other variables that might impact the outcomes (e.g. Murray et al., 2009). Based on risk research (e.g. Gendreau et al., 1996; Harris et al., 1993; Klassen and O’Connor, 1994; Kurlychek et al., 2006; Social Exclusion Unit, 2002; Visher and Courtney, 2006; Webster et al., 1997), objective measures of the men's age, income, employment, number of alcohol units consumed and illegal drug use in the year before prison and involvement with the criminal justice system (CJS) were used as control variables (measured at Time 1). The men's involvement with the CJS was measured by calculating the mean score of their sentence length, total time in prison, number of prison sentences and number of previous convictions. These raw scores were standardized to $\mathrm{z}$ scores for the analysis. 
Table I. Means and standard deviations of the man's resettlement outcomes at Time 2 and bivariate inter-correlations between the outcomes.

\begin{tabular}{lrlllllll}
\hline & $M$ & $(S D)$ & Accomm. & Emp. & Health & $\begin{array}{l}\text { Alc. \& } \\
\text { drugs }\end{array}$ & Finances & $\begin{array}{l}\text { Family } \\
\text { rels. }\end{array}$ \\
\hline Accommodation & 1.92 & $(1.53)$ & & & & & & \\
Employment & 3.10 & $(1.14)$ & .11 & & & & & \\
Health & 11.82 & $(8.31)$ & .28 & .09 & & & & \\
Alcohol \& drugs & 1.87 & $(1.38)$ & $.67^{* *}$ & .09 & $.38^{*}$ & & & \\
Finances & 2.97 & $(1.11)$ & .25 & $.44^{* *}$ & .19 & $.34^{*}$ & & \\
Family relationships & 3.68 & $(1.09)$ & $-.75^{* *}$ & -.24 & $-.41^{* *}$ & $-.49^{* *}$ & -.27 & \\
Coping competence & 41.82 & $(4.71)$ & -.31 & -.09 & $-.48^{* *}$ & -.26 & -.04 & $.44^{* *}$ \\
\hline
\end{tabular}

Note: $M=$ Mean, $S D=$ Standard Deviation; $* p<0.05 ; * * p<0.0$ I, two-tailed.

\section{Results}

\section{Descriptive data}

The mean score on the family relationships before prison measure was $3.64(\mathrm{SD}=0.71)$, and $3.95(\mathrm{SD}=0.87)$ for contact during the imprisonment. The bivariate correlation between the measures was, $r=0.32, p=.05$.

Descriptive statistics for the men's scores in the seven outcomes are given in Table 1.

The findings suggest that the men experienced relatively little difficulty with accommodation after release but regarded finding employment more difficult. They had few health problems as indicated by their reasonably low average score on the GHQ. They reported less difficulty with alcohol and drugs than with money. Their family relationships were moderately good and they scored relatively highly on the coping ability measure.

Table 1 shows the inter-correlations between the outcomes at Time 2 .

The inter-correlations between outcome measures showed differentiated results. Difficulty with accommodation was positively correlated with difficulty with alcohol and drugs and negatively with family relationships. Health problems were associated with difficulty with alcohol and drug use, less positive family relationships and coping ability. Difficulty with alcohol and drugs was associated with problems with finances and family relationships. Coping ability scores were negatively associated with health problems and positively associated with family relationships. Difficulties with employment and finances were significantly associated.

An exploratory principle component factor analysis using Oblimin rotation was conducted with the seven resettlement outcomes to assess whether they could be grouped together to reflect latent constructs of resettlement. The analysis revealed two components with Eigenvalues exceeding 1. These explained 43.16 per cent and 18.40 per cent of the variance, respectively. The rotated solution showed the following high loadings: Factor 1 consisted of difficulty with accommodation (0.79), health (0.69), alcohol and drugs $(0.70)$, quality of family relationships $(-0.80)$ and ability to cope $(-0.71)$. Factor 2 was formed primarily by difficulty with employment $(0.82)$ and financial problems 
(0.82). Although there were also minor loadings of other variables the two components indicate two relatively independent domains of (a) social and emotional problems, and (b) work and financial problems.

With regard to the men's descriptive statistics on the control variables we present the median in cases of strongly skewed distributions, otherwise the mean. The weekly household income at Time 1 was $M d=£ 371.88$, and they consumed $M d=8.5$ units of alcohol per week, on average. Their average sentence length was $M=2.31$ years (SD = 1.31 ) and they had spent on average $M d=1.75$ years in prison in their lifetime. They had $M=3.62(\mathrm{SD}=3.48)$ previous prison sentences and $M d=10$ previous convictions. A total of 53.8 per cent of the men were employed at the time of their arrest and 69.2 per cent had used illegal drugs in the year before their imprisonment.

The men's contact with the CJS was most consistently significantly related to the other control variables (age, $r=0.48$, and employment, $r=-0.33$ ) and the outcomes of accommodation, $(r=0.34)$, alcohol and drugs, $(r=0.47)$, and financial problems, $(r=$ $0.33)$, and coping ability, $(r=-0.33)$. Age was significantly correlated with health problems, $(r=0.57)$, and income with employment difficulty, $(r=-0.44)$. Other control variable inter-correlations were not significant but in the expected direction. For example, income and employment were negatively related to contact with the CJS and with alcohol units and drug use.

\section{Family relationships predicting the outcomes}

To investigate the association between family relationships at Time 1 and the outcomes at Time 2, bivariate correlations and hierarchical regressions were conducted. In the latter analyses the control variables were entered first, and then the family relationships predictor was entered to predict the outcomes. In order to compare the results of the regression analysis with the bivariate correlations, the square root of the additional variance explained by family relationships was used as a measure of effect size where risk factors were controlled. The results are presented in Table 2.

Positive family relationships significantly predicted less difficulty with accommodation, alcohol and drugs, better family relationships and coping ability after release. Difficulty with employment, health and finance were not significantly predicted by family relationships. These results are also reflected in the correlations with the scores in the two factors of the outcomes. The correlation with the interpersonal relationships factor of the outcomes was highly significant.

When controlling for the various other risk variables, family relationships remained a significant predictor of better outcomes with accommodation, alcohol and drugs, family relationships and coping ability after release. The effect sizes were medium to large. The correlation with the interpersonal relationships factor of the outcomes remained significant.

\section{Discussion}

The present study investigated whether prisoners' family relationships with their (ex-) partner and children before and during imprisonment support resilience in resettlement 
Table 2. Bivariate and adjusted correlations (square root of additional variance explained) for family relationships predicting the man's Time 2 resettlement outcomes.

\begin{tabular}{lll}
\hline Man's Time 2 resettlement pathways & \multicolumn{2}{l}{ Family relationships } \\
\cline { 2 - 3 } & $\begin{array}{ll}\text { Bivariate } \\
\text { correlation }(r)\end{array}$ & $\begin{array}{l}\text { Adjusted } \\
\text { correlation }\left(r_{\text {adj }}\right)\end{array}$ \\
\hline Accommodation & $-0.77^{* *}$ & $-0.67^{* *}$ \\
Employment & 0.05 & 0.00 \\
Health & -0.29 & -0.25 \\
Alcohol \& drugs & $-0.62^{* *}$ & $-0.52^{* *}$ \\
Finances & -0.19 & -0.07 \\
Family relationships & $0.70^{* *}$ & $0.73^{* *}$ \\
Coping competence & $0.47^{* *}$ & $0.30^{*}$ \\
Social and emotional problems (Factor I) & $-0.78^{* *}$ & $-0.68^{* *}$ \\
Work and financial problems (Factor 2) & -0.11 & -0.08 \\
\hline
\end{tabular}

Note: $* p<0.05 ; * p<0.01$, two-tailed.

as indicated by positive post-release outcomes in accommodation, employment, health, alcohol and drug dependency, finances, family relationships and coping skills. There are two main findings of our study. First, it showed that there are substantial correlations between family relations and the seven outcomes, even after controlling for commonly reported personal and social risk factors. Second, the relations were clearly different across the outcomes. The development of resilience was indicated by accommodation, alcohol and drugs, family relationships and coping ability outcomes. With regard to health outcomes, there was a weaker, but non-significant tendency. In contrast, family relationships did not predict outcomes in employment or finances. The findings show that positive family relationships are important for developing resilience after release from prison and therefore may have an impact on the desistance process.

The potential mechanisms of how family relationships may help to develop resilience in resettlement can be understood from social bonding and social capital theories. According to social bonding theory, family relationships may have encouraged resilience in resettlement through the attachment that the men had with their families. This attachment supported social reintegration and may have influenced other aspects of bonding that were not directly measured in this study (commitment to mainstream societal goals, endorsement of a common value system and involvement in associated social activities) (Hirschi, 2011). In particular, the men's better outcomes with alcohol and drug use are in line with such an interpretation. Positive family relationship also predicted coping abilities, which also supports the theory.

The prisoners' family network could also have provided material resources such as accommodation after their release. Those with good family relationships had less accommodation difficulties. If the men were living with the children's mother, as was the case for approximately two-thirds of the sample, they did not have serious housing problems. The prisoners' access to social capital may not only have helped them to become resilient in response to challenges such as alcohol and drug abuse after release but also promoted 
a sense of coping ability through the ways that Hagan and McCarthy (1997) describe. The strong relation to the men's positive family relationships outcome is more or less self-evident as one could expect some continuity between good family relationships before, during and after imprisonment. However, it is not trivial because imprisonment is a very stressful critical life event that may deteriorate positive family relationships. Although an unrealistically positive view of one's own coping ability may be counterproductive (e.g. Souza et al., 2013) negative emotions reduce the capacity of resilience in difficult circumstances (Lösel and Bender, 2003; Masten, 2007).

In contrast to the protective function of positive family relationships on the social and emotional outcomes we did not observe any significant relationship with work and financial problems. This finding deviates from past studies that have reported a positive relationship between family bonds and employment in ex-prisoners (e.g. Berg and Huebner, 2011). However, Mills and Codd (2008) argue that different family members provide different types of social capital. For example, parents may be better able to provide employment opportunities because of their longer work history, while partners may be better placed to offer accommodation. This reasoning makes sense in light of the present findings.

In addition, there are other issues that make our findings plausible. First, our study covered a relatively short time period of resettlement during which the impact of family ties on economic factors may not yet have been much developed. Second, the offenders' employment and financial status may be more dependent on factors such as education and qualifications, the labour market and stigmatization processes. Third, post-release resettlement and relapse prevention programmes could have targeted employment and finances, making the impact of family protective factors less salient.

The differential patterns of the relationship between the protective family factors and the various dimensions of resettlement are underlined by the factor analysis that showed two independent dimensions. One component comprised problems with accommodation, alcohol and drug use, health, quality of family relations and coping ability. In contrast to these more social and emotional aspects, the second factor consisted of finance and work difficulties. Apart from alcohol and drugs, none of the pathways in the first factor were correlated with either employment or finances.

Most of our findings are in accordance with research on family relationships and resettlement in North America (e.g. Visher and Courtney, 2007). Within this broader context and particularly with regard to the respective state of research in Europe our study has various strengths. Most studies on the role of family relationships in resettlement have focused only on reoffending measures. Our focus on seven outcomes provides a more holistic and resilience-orientated picture of resettlement experiences. In addition, because of the difficulty in obtaining whole family data on this topic, the majority of research seeks the view of the prisoner only, whereas this study succeeded in utilizing a complete set of multi-informant data to form the measure of family relationships. As mentioned, prisoners may adopt an optimism bias when forecasting or estimating events (Burnett, 1992; Dhami et al., 2006; Visher et al., 2003; Zamble and Quinsey, 1997). Therefore, a multi-informant approach that integrates prisoners' (ex-) partners' responses may provide a more balanced view (Souza et al., 2013).

However, there are also some limitations of our study which prevent too far-reaching generalizations: the sample size was relatively small and BAME families were slightly 
under-represented at Time 2. Related to this, reduced statistical power prevented the detection of small effects. Further, the study's design precluded representation of prisoners with no resettlement address or those who planned to resettle outside of London or East Anglia. Self-selection may have also influenced the final composition of the sample, in which less troubled families may have been more likely to consent to participate. Although the relatively low means in the experiences of difficulties point in this direction (see Table 1) couples may have participated because they hoped for some advice or counselling. Although comparable to the national prison population on age and offence type, many prisoners in our study were serving relatively short sentences (on average 2.3 years), whereas the imprisonment and resettlement experiences of longer-term prisoners may be different.

A further limit is the focus on male prisoners and their heterosexual relationships. Although this constellation is most prevalent it should not be generalized to other lifestyles. Dunn (2013: 6) highlights the diversity of prisoners' family relationships, citing the 'cycle of invisibility' of lesbian, gay, transgender and transsexual prisoners. The present study cannot offer insights into these relationships and the limitations of the findings and their policy implications in this respect must be acknowledged. To reflect the diversity of prisoners' family relationships (e.g. female prisoners, same-sex relationships) would have required a more comprehensive study of resettlement (e.g. Cobbina et al., 2012), which was not possible due to limited resources. However, research on this topic is needed.

As mentioned, a further limitation is the rather short time period of six months after release. Further longer-term follow-ups would give a fuller, more dynamic picture of the development of resilience in resettlement and its relation to reoffending. However, this was not possible within the time-frame of the present study. The measures in this study were largely based on self-reports of the men and women and were relatively simple (i.e. based on a few interview items). Such data may be less reliable than more comprehensive psychometrically validated measures. However, as our interviews covered a broad range of topics it was not feasible to apply lengthy instruments on each of the constructs. We formed various aggregated indices and our assessment was similar to what is normally possible in this field of research practice (e.g. La Vigne et al., 2004; LeBel et al., 2008; Visher and Courtney, 2006, 2007). Using contact during imprisonment as one of our indicators of the quality/intensity of family relationships is also not without problems because of the practical difficulties in maintaining contact that many families encounter (Mills and Codd, 2008). However, unlike other research our measure of contact included letters and telephone calls which is likely to be more representative of contact than visits alone. Of course, one must also assume influences of positive self-presentation by the participants, however, these are general research problems (Lösel and Schmucker, 2002) and not specific to this study.

With these limitations in mind the present study suggests the positive influence of family relationships in various important areas of resettlement. In agreement with the practice-orientated literature it suggests that supporting family relationships and facilitating the maintenance of these relationships during imprisonment could support the development of resilience in response to certain resettlement challenges. The findings suggest that resilience can be developed through family networks which provide 
important tangible (e.g. accommodation) and non-tangible (e.g. emotional support) resources in resettlement.

This finding is important because it can usefully inform efforts to reduce problems and improve lives. It is relevant to policy that is aimed at facilitating resettlement and encouraging desistance. For example, it adds further weight to the argument that communication between prisoners, families and prisons should be improved. Where appropriate, families could be more involved in the prisoners' sentence progression, for example, by attending programme sessions and review meetings. As other findings from our study have shown (Souza et al., 2013), the female partners often have a more realistic expectation of resettlement problems that could help to reduce later coping problems. Such broader family-related perspectives have shown rather positive effects for young offenders (e.g. Henggeler et al., 2009), however basic elements could also be included in rehabilitation programmes for adult offenders. In addition, interventions to support relationships could be targeted at the prevention stage for vulnerable families, rather than after problems have developed. For example, the Troubled Families Programme in England and Wales recognizes the importance of such early intervention (Communities and Local Government, 2012), and aims to support families with multiple social and economic problems to try to interrupt the generational cycle of relationship breakdown, mental and physical health problems and crime. Our findings also highlight the multidimensional, interconnected nature of resettlement experiences. Future research and policy should aim to take into account this complexity in addition to acknowledging the importance of a more nuanced definition of the concept of family. Policies that address multiple resettlement problems in an integrated mode may be more successful than ones which target areas in relative isolation (Maguire et al., 2010). Encouraging collaboration and communication between service providers could support a more 'joined up' approach to resettlement and reducing reoffending. This is in accordance with recommendations to widen the 'what works' approach to a systems perspective and link it to research on natural protective factors and desistance (Farrall, 2002; Lösel, 2012b; McNeill, 2006; Maguire et al., 2010). Following a 'translational criminology' perspective, future studies should replicate the findings using large, representative samples and apply controlled evaluation designs to transfer correlational data into policy and practice.

\section{Acknowledgements}

The authors would like to thank NOMS for allowing access to the prisons in the study.

\section{Funding}

The research was carried out in collaboration between Ormiston and the Institute of Criminology, University of Cambridge. The work was supported by the Big Lottery Fund.

\section{References}

Adorjan M and Chui WH (2012) Making sense of going straight: Personal accounts of male exprisoners in Hong Kong. British Journal of Criminology 52(3): 577-590.

Bales WD and Mears DP (2008) Inmate social ties and the transition to society: Does visitation reduce recidivism? Journal of Research in Crime and Delinquency 45(3): 287-321. 
Baumer EP, O'Donnell I and Hughes N (2009) The porous prison: A note on the rehabilitative potential of visits home. The Prison Journal 89(1): 119-126.

Bender D and Lösel F (2009) A Brief Resilience Scale. Bavaria: University of Erlangen-Nuremberg, Institute of Psychology.

Berg MT and Huebner BM (2011) Reentry and the ties that bind: An examination of social ties, employment and recidivism. Justice Quarterly 28(2): 382-410.

Berman G (2011) Prison Population Statistics. London: House of Commons.

Bourdieu P (1986) The forms of capital. In: Richardson JG (ed.) Handbook of Theory and Research for the Sociology of Education. Connecticut: Greenwood Press, 241-258.

Braman D (2004) Doing Time on the Outside: Incarceration and Family Life in Urban America. Ann Arbor, MI: University of Michigan Press.

Burnett R (1992) The Dynamics of Recidivism. Oxford: Centre for Criminological Research.

Cicchetti D (2010) Resilience under conditions of extreme stress: A multi-level perspective. World Psychiatry 9(3): 145-154.

Cobbina JE, Huebner BM and Berg MT (2012) Men, women, and post release offending: An examination of the nature of the link between relational ties and recidivism. Crime and Delinquency 58(3): 331-361.

Collishaw S, Pickles A, Messer J, et al. (2007) Resilience to adult psychopathology following childhood maltreatment: Evidence from a community sample. Child Abuse and Neglect 31(3): 211-229.

Communities and Local Government (2012) The Troubled Families Programme: Financial Framework for the Troubled Families Programme's Payment-by-Results Scheme for Local Authorities. London: Communities and Local Government.

Davis C, Bahr SJ and Ward C (2012) The process of offender reintegration: Perceptions of what helps prisoners reenter society. Criminology and Criminal Justice 13(4): 446-469.

Dhami MK, Mandel DR, Loewenstein G, et al. (2006) Prisoners' positive illusions of their postrelease success. Law and Human Behavior 30(6): 631-647.

Dunn P (2013) Slipping off the equalities agenda? Work with LGBT prisoners. Prison Service Journal 206: 3-10.

Farrall S (2002) Rethinking What Works with Offenders: Probation, Social Context and Desistance from Crime. Cullompton, Devon: Willan.

Farrall S (2004) Social capital and offender reintegration: Making probation desistance focused. In: Maruna S and Immarigeon R (eds) After Crime and Punishment. Cullompton, Devon: Willan, 57-82.

Farrall S and Calverley A (2006) Understanding Desistance from Crime: Emerging Theoretical Directions in Resettlement and Rehabilitation. Maidenhead: Open University Press.

Field J (2003) Social Capital. London: Routledge.

Fitzpatrick C (2011) What is the difference between 'desistance' and 'resilience'? Exploring the relationship between two key concepts. Youth Justice 11(3): 221-234.

Flouri E (2006) Parental interest in children's education, children's self-esteem and locus of control, and later educational attainment: Twenty-six year follow-up of the 1970 British Birth Cohort. British Journal of Educational Psychology 76(Pt 1): 41-55.

Flouri E (2007) Early family environments may moderate prediction of low educational attainment in adulthood: The cases of childhood hyperactivity and authoritarian parenting. Educational Psychology 27(6): 737-751.

Gendreau P, Little T and Goggin C (1996) A meta-analysis of the predictors of adult offender recidivism: What works! Criminology 34(4): 575-608.

Goldberg DP (1978) Manual of the General Health Questionnaire. NFER: Windsor.

Hagan J and McCarthy B (1997) Mean Streets. Cambridge: Cambridge University Press. 
Harris GT, Rice ME and Quinsey VL (1993) Violent recidivism of mentally disordered offenders: The development of a statistical prediction instrument. Criminal Justice and Behavior 20(4): 315-335.

Hawkins JD, Catalano RF, Morrison DM, et al. (1992) The Seattle Social Development Project: Effects of the first four years on protective factors and problem behaviors. In: McCord J and Tremblay RE (eds) Preventing Antisocial Behaviour: Interventions from Birth to Adolescence. New York: The Guildford Press, 139-161.

Henggeler S, Schoenwald S, Borduin C, et al. (2009) Multisystemic Therapy for Antisocial Behavior in Children and Adolescents. New York: Guilford.

Hirschi T (2002) Causes of Delinquency. New Jersey: Transaction.

Hirschi T (2011) Social bond theory. In: Cullen FT and Agnew R (eds) Criminological Theory: Past to Present. New York: Oxford University Press, 215-223.

Home Office (2004) Reducing Reoffending: National Action Plan. London: Home Office.

Jackson J, Bradford B, Hough M, et al. (2013) Compliance with the law and policing by consent: Notes on police and legal legitimacy. In: Crawford A and Hucklesby A (eds) Legitimacy and Compliance in Criminal Justice. London: Routledge, 29-49.

Jamieson R and Grounds A (2005) Release and adjustment: Perspectives from studies of wrongly convicted and politically motivated prisoners. In: Liebling A and Maruna S (eds) The Effects of Imprisonment. Cullompton: Willan, 33-65.

Klassen D and O'Connor W (1994) Demographic and case history variables in risk assessment. In: Monahan J and Steadman HJ (eds) Violence and Mental Disorder: Developments in Risk Assessment. Chicago, IL: University of Chicago Press, 229-258.

Kleinke C, Stemmler M, Reinecke J, et al. (2011) Efficient ways to impute incomplete panel data. Advances in Statistical Analysis 95(4): 351-373.

Kurlycheck MC, Brame R and Bushway SD (2006) Scarlett letters and recidivism: Does an old criminal record predict future offending? Criminology \& Public Policy 5(3): 438-504.

Lanskey C, Lösel F, Markson L, et al. (2014) Children's contact with imprisoned fathers and the father child relationships after release: An interactional perspective. Families, Relationships and Societies. Epub ahead of print 22 August 2014. Available at: dx.doi.org/10.1332/20467 4314X14037881746154.

Laub JH and Sampson RJ (2003) Shared Beginnings, Divergent Lives: Delinquent Boys to Age 70. Cambridge, MA: Harvard University Press.

Laub JH, Nagin DS and Sampson RJ (1998) Trajectories of change in criminal offending: Good marriages and the desistance process. American Sociological Review 63(2): 225-238.

La Vigne NG, Naser RL, Brooks LE, et al. (2005) Examining the effect of incarceration and inprison family contact on prisoners' family relationships. Journal of Contemporary Criminal Justice 21(4): 314-335.

La Vigne NG, Visher C and Castro J (2004) Chicago Prisoners' Experiences Returning Home. Washington, DC: The Urban Institute.

LeBel TP, Burnett R, Maruna S, et al. (2008) The 'chicken and egg' of subjective and social factors in desistance from crime. European Journal of Criminology 5(2): 131-159.

Lösel F (2012a) Towards a third phase of 'what works' in offender rehabilitation. In: Loeber R and Welsh BC (eds) The Future of Criminology. New York: Oxford University Press, 196-203.

Lösel F (2012b) Offender treatment and rehabilitation: What works? In: Maguire M, Morgan R and Reiner R (eds) The Oxford Handbook of Criminology. Oxford: Oxford University Press, 986-1006.

Lösel F and Bender D (2003) Protective factors and resilience. In: Farrington DP and Coid JW (eds) Early Prevention of Adult Antisocial Behaviour. Cambridge: Cambridge University Press, 130-204. 
Lösel F and Farrington DP (2012) Direct protective and buffering protective factors in the development of youth violence. American Journal of Preventive Medicine 43(2S1): 8-23.

Lösel F and Schmucker M (2002) Assessor's biases. In: Fernandez-Ballesteros R (ed) Encyclopedia of Psychological Assessment. London: Sage, vol. 1, 98-101.

Lösel F, Pugh G, Markson L, et al. (2012) Risk and Protective Factors in the Resettlement of Imprisoned Fathers with Their Families. Ipswich: Ormiston Children's and Families Trust.

Luthar SS, Cicchetti D and Becker B (2000) The construct of resilience: A critical evaluation and guidelines for future work. Child Development 71(3): 543-562.

McGuire J (1995) What Works: Reducing Reoffending. Guidelines from Research and Practice. Chichester: Wiley.

McNeill F (2006) A desistance paradigm for offender management. Criminology and Criminal Justice 6(1): 39-62.

Maguire M and Raynor P (2006) How the resettlement of prisoners promotes desistance from crime: Or does it? Criminology and Criminal Justice 6(1): 19-38.

Maguire M, Grubin D, Lösel F, et al. (2010) What works' and the Correctional Services Accreditation Panel: Taking stock from an inside perspective. Criminology and Criminal Justice 10: 37-58.

Maruna S (2001) Making Good: How Ex-Convicts Reform and Rebuild Their Lives. Washington, DC: American Psychological Association.

Masten AS (2007) Resilience in developing systems: Progress and promise as the fourth wave rises. Development and Psychopathology 19(3): 921-930.

Masten AS (2011) Resilience in children threatened by extreme adversity: Frameworks for research, practice, and translation synergy. Development and Psychopathology 23(2): 493506.

May C, Sharma N and Stewart D (2008) Factors Linked to Reoffending: A One-Year Follow-Up of Prisoners Who Took Part in the Resettlement Surveys 2001, 2003 and 2004. London: Home Office.

Mills AL and Codd H (2008) Prisoners' families and offender management: Mobilizing social capital. Probation Journal: The Journal of Community and Criminal Justice 55(1): 9-24.

Ministry of Justice (2010) Compendium of Reoffending Statistics and Analysis. London: Ministry of Justice.

Ministry of Justice (2012) Prisoners' Childhood and Family Backgrounds: Results from the Surveying Prisoner Crime Reduction (SPCR) Longitudinal Cohort Study of Prisoners. London: Ministry of Justice.

Morris P (1965) Prisoners and Their Families. Woking: Unwin Brothers.

Murray J, Farrington DP and Eisner MP (2009) Drawing conclusions about causes from systematic reviews of risk factors: The Cambridge Quality Checklists. Journal of Experimental Criminology 5(1): 1-23.

Murray J, Farrington DP and Sekol I (2012a) Children's antisocial behaviour, mental health, drug use, and educational performance after parental incarceration: A systematic review and meta analysis. Psychological Bulletin 138(2): 175-210.

Murray J, Loeber R and Pardini D (2012b) Parental involvement in the criminal justice system and the development of youth theft, depression, marijuana use, and poor academic performance. Criminology 50(1): 255-302.

Naser RL and Visher CA (2006) Family members' experiences with incarceration and re-entry. Western Criminology Review 7(2): 20-31.

Niven S and Stewart D (2005) Resettlement Outcomes on Release from Prison in 2003. Home Office Research Findings 248. London: Home Office. 
Pettit B and Lyons CJ (2009) Incarceration and the legitimate labour market: Examining agegraded effects on employment and wages. Law and Society Review 43(4): 725-756.

Prison Reform Trust (2009) Bromley Briefings: Prison Fact File. London: Prison Reform Trust. Prison Reform Trust (2010) Bromley Briefings: Prison Fact File. London: Prison Reform Trust.

Rosenfeld R, Messner SF and Baumer EP (2001) Social capital and homicide. Social Forces 80(1): 283-309.

Rutter M (2012) Resilience as a dynamic concept. Development and Psychopathology 24(2): 335-344.

Sampson RJ and Laub JH (1993) Crime in the Making: Pathways and Turning Points through Life. Cambridge, MA: Harvard University Press.

Shapland J, Bottoms A and Muir G (2012) Perceptions of the criminal justice system among young adult would-be desisters. In: Lösel F, Bottoms AE and Farrington DP (eds) Young Adult Offenders: Lost in Transition? Milton Park: Routledge, 128-145.

Social Exclusion Unit (2002) Reducing Reoffending by Ex-Prisoners. London: Social Exclusion Unit.

Souza KA, Lösel F, Markson L, et al. (2013) Pre-release expectations and post-release experiences of prisoners and their (ex-)partners. Legal and Criminological Psychology. Epub ahead of print 11 November 2013. DOI: 10.1111/lcrp.12033.

Theobald D and Farrington DP (2013) The effects of marital breakdown on offending: Results from a prospective longitudinal survey of males. Psychology, Crime and Law 19(4): 391-408.

Visher CA and Courtney SME (2006) Cleveland Prisoners' Experiences Returning Home. Washington, DC: The Urban Institute.

Visher CA and Courtney SME (2007) One Year Out: Experiences of Prisoners Returning to Cleveland. Washington, DC: The Urban Institute.

Visher CA and Travis J (2003) Transitions from prison to community: Understanding individual pathways. Annual Review of Sociology 29(1): 89-113.

Visher CA, Baer D and Naser R (2006) Ohio Prisoners' Reflections on Returning Home. Washington, DC: The Urban Institute.

Visher CA, La Vigne NG and Castro JL (2003) Returning home: Preliminary findings from a pilot study of soon-to-be-released prisoners in Maryland. Justice Research \& Policy 5(2): 55-74.

Webster CD, Douglas KS, Eaves D, et al. (1997) HCR-20: Assessing Risk for Violence. Version 2. British Columbia, Canada: Mental Health Law and Policy Institute.

Wildeman C (2010) Paternal incarceration and children's physically aggressive behaviors: Evidence from the Fragile Families and Child Wellbeing Study. Social Forces 89(1): 285-310.

Zamble E and Quinsey VL (1997) The Criminal Recidivism Process. Cambridge: Cambridge University Press.

\section{Author biographies}

Lucy Markson is a final year doctoral researcher in the Department of Psychology at the University of Cambridge, United Kingdom. She is also a Visiting Scholar at the Institute of Criminology, University of Cambridge. Her doctoral research examines cumulative economic and social risks and within-family protective factors as explanatory variables of the different ways that paternal imprisonment impacts families.

Friedrich Lösel is Director Emeritus of the Institute of Criminology at Cambridge University and Professor of Psychology at the University of Erlangen-Nuremberg, Germany. He has published ca. 20 books and 380 articles. In recognition of his work, he has received the European Psychology \& Law Award, the Sellin-Glueck and Experimental Criminology Awards from the American Society of Criminology, the German Psychology Prize and the Stockholm Prize in Criminology. 
Karen Souza is currently a doctoral candidate in psychology at City University London, United Kingdom. She is also a Visiting Scholar at the Institute of Criminology, University of Cambridge. Karen's current research interests are in prisoner resettlement, youth violence prevention and community justice interventions.

Caroline Lanskey is an Affiliated Lecturer at the Institute of Criminology, University of Cambridge. Her research interests centre on the impact of criminal justice processes on young people and families with particular reference to the themes of education, citizenship, voice and well-being. 